\title{
NOISE REDUCTION FOR BALLASTED TRACK: A COMPARATIVE SOCIO-ECONOMIC ASSESSMENT
}

\author{
JOHN ARMSTRONG ${ }^{1}$, ALEJANDRO ORTEGA $^{1}$, SIMON BLAINEY $^{1}$, JOHN PRESTON ${ }^{1}$, DAVID \\ THOMPSON $^{2}$, GIACOMO SQUICCIARINI ${ }^{2} \&$ EVANGELOS NTOTSIOS $^{2}$ \\ ${ }^{1}$ Transportation Research Group, University of Southampton, UK. \\ ${ }^{2}$ Institution of Sound and Vibration Research, University of Southampton, UK.
}

\begin{abstract}
Transport infrastructure produces many externalities. Increased accessibility and the resultant economic development are among the most notable positive ones. Accidents, air and noise pollution and other environmental issues, such as impacts on biodiversity, landscape and townscape, are the most important negative ones. In the case of railway infrastructure, noise impacts have a key effect on net social benefit. Noise reduction is crucial to achieve greater social benefits. Against this background, the University of Southampton has been undertaking the Track to the Future (T2F) project, which is assessing, among other issues, how to produce a quiet ballasted track system that at the same time is cheaper to maintain and renew.

This paper considers combinations of engineering interventions that could reduce rail-related noise, including under sleeper pads, rail dampers and noise barriers which all reduce noise emissions. It extends previous analysis of under sleeper pads to compare their costs and benefits with those of rail dampers and noise barriers in the context of a UK-based installation case study.

Keywords: comfort, cost-benefit analysis, noise, noise barriers, rail dampers, railway, under sleeper pads, upgrades
\end{abstract}

\section{INTRODUCTION}

In many parts of the world, including Great Britain, growth in demand for rail transport in recent decades has resulted in networks (or parts thereof) nearing capacity limits, reducing potential for further traffic growth [1]. In addition to capacity issues, increasing traffic levels impose additional loads upon the infrastructure, accelerating deterioration of track components. This can be mitigated through routine maintenance and renewal activities, but these incur costs and can cause significant disruption to services, and the increasing levels of which also reduce opportunities for access to the infrastructure. To accommodate increased service frequencies and faster and heavier trains, while also reducing maintenance requirements, opportunities to improve railway track quality and lifespan, and reduce maintenance requirements, should be taken [2], as long as there is a positive business case for doing so. Several potential advances in track and sub-base construction and maintenance procedures could lead to improvements in reliability, reduced travel times and reductions in perceived noise (amongst other benefits) [2]. As with the planning process for other capital-intensive transport investments, the business cases for such interventions should be determined by means of economic appraisal. Widely used approaches include cost-benefit analysis (CBA) to compare the benefits and costs of a project/investment, input-output tables to assess the effects of investments on regional or sectoral economies and multi-criteria analysis to rank alternative proposals according to investment preferences. When applying these tools, the financial valuation of costs and benefits is crucial, since they are central to the outputs of the analysis [3], with any errors distorting the results and potentially resulting in inappropriate investment decisions. Although this uncertainty cannot be completely eliminated [4], every 
reasonable effort should be made to maximise the accuracy of the cost and benefit valuations used in such analyses [5].

The Track to the Future (T2F) research project [6], upon which this paper is based, has three main aims:

- To develop low-maintenance, long-life track systems with optimised material use in terms of whole life cost and embedded carbon

- To design crossings and transitions so as to optimise vehicle behaviour through them and hence maximise resistance to damage

- To develop an integrated approach to designing a low-noise, low-vibration track

One of the project components is the development of integrated cost and carbon modelling tools, enabling systematic assessment of a range of infrastructure and other interventions.

An extensively used means of upgrading railway track in Europe is the installation of under sleeper pads (USPs), elastic elements made usually of rubber which are fixed beneath the sleepers in ballasted track and influence the track behaviour. Their effects have been widely studied, with particular emphasis on their beneficial effects on track quality and vibration reduction [7]. However, an apparent gap was found in the literature regarding the socioeconomic effects of track renewals, limiting the evidence available to railway infrastructure managers (IMs) when considering upgrades to existing track. Previous work [8] by some of this paper's authors appeared to be the sole example of recent research on the social costs and benefits of USP installation. Further work in this area was, therefore, undertaken, as described in [9], to provide useful information for IMs and policymakers considering the use of USPs to upgrade existing track. The work described in [9] included a review of noise and other valuations associated with USP installation and the application of a CBA to a case study of hypothetical USP installation on a major commuter route in southern England. This paper extends the work described in [9] to the installation of rail dampers or noise barriers and a comparative analysis of the resulting costs and benefits.

Following this introduction, the paper has four further main sections. First, the findings of the review described in [9] are summarised. Next, the expanded case study is presented. Ongoing and further work is then described, followed finally by some conclusions. These main sections are followed by acknowledgements and a list of references.

\section{VALUES OF NOISE, VIBRATION, RIDE QUALITY AND COMFORT}

\subsection{Overview}

Railway-generated noise affects both users (passengers) and non-users (living or working nearby), but the recent, relevant literature focusses overwhelmingly on non-user effects.

Railway noise is considered to be more similar to aircraft than road traffic noise (intermittent peaks, with very low background levels) [10] and to be less disturbing than the latter, a further benefit of modal shift from road to rail. However, De Coensel et al. [11] found no statistical evidence of reduced disturbance. Noise perception follows a logarithmic scale, so marginal effects of additional noise diminish as background levels rise [12].

The social costs of noise can be divided into three partially overlapping components [10]: resource costs (medical and health service costs), opportunity costs (lost productivity and foregone leisure) and general disutility (other social and economic costs, including 
discomfort, inconvenience and wider anxiety and concern), of which the last dominates [13] and should be the primary focus. Its economic costs may include reduced property values and inhibition of development adjacent to railways [14]. There are significant variations between noise emission and perception, due to intervening distances, weather conditions and the presence or not of screening effects, as well as background noise levels and people's varying attitudes towards railway noise [14], making the effects difficult to generalise [15].

Three main methods have been used to evaluate noise costs: (i) hedonic pricing (HP), (ii) stated preference (SP) surveys (used to determine willingness to pay (WTP) or contingent valuation $(\mathrm{CV})$ ) and (iii) estimation of abatement costs. WTP values can be obtained from HP as well as from SP surveys, although this can cause problems [16], since HP methods tend to overestimate noise nuisance valuations relative to SP surveys. There are also differences between results obtained from alternative SP approaches [17].

\subsection{Costs of annoyance per person}

WTP studies of railway noise reduction in the UK and the Netherlands $[18,19]$ found no effects on the housing market below $55 \mathrm{~dB}(\mathrm{~A})$. However, the UK Department for Transport [20] sets this threshold at $45 \mathrm{~dB}(\mathrm{~A})$, and Nijland et al. [19] noted that people may be disturbed by noise levels as low as $40 \mathrm{~dB}(\mathrm{~A})$, suggesting that consumer behaviour towards noise exposure differs from its effects on health and well-being. Earlier German work [21], quoted in [14], also presented monthly per-person WTP values for different noise reduction levels.

A noise abatement cost approach by Oertli \& Wassmer [22] estimated the cost of using noise barriers in Switzerland to deliver a $1 \mathrm{~dB}(\mathrm{~A})$ reduction in noise per inhabitant per month, but their estimated bounds were not precise. Two reports cited by Brons et al. [14] used the same measure. Weinberger et al. [21] produced the per-person cost of abatement to comply with a given limit, and Tyssen [23] calculated costs per residential unit in the Netherlands, again to comply with a given limit. The results vary significantly, however, with the costs in [23] appearing to be an order of magnitude larger than those in [21, 22].

\subsection{Property value depreciation}

Strand \& Vagnes [16] calculated an elasticity of property value with respect to distance for the relationship between residential property prices and proximity to railways, using HP-derived valuations supported by surveys of real estate agents. Howarth et al. [24] also estimated the effect of railway noise on property values while applying a damage assessment methodology to various environmental impacts of transport in the Netherlands. Another Dutch study [25] presented results in the same format, with two sets of depreciation estimates based on HP and CV. An earlier British HP study [26] considered a range of surface transport costs and charges and estimated a Noise Depreciation Sensitivity Index giving the percentage reduction in property values for a $1 \mathrm{~dB}(\mathrm{~A})$ increase in noise levels, although disaggregated only into low, medium and high noise levels. Bateman, Day \& Lake [27] similarly found reductions in property prices in Birmingham (UK), with the decline in valuation again depending on the noise level. This study was extended [28] to cover the entire UK, presenting the results in terms of WTP per household or person per annum.

An HP model in the Netherlands found a maximum discount for noise levels above $65 \mathrm{~dB}(\mathrm{~A})$ and, by contrast, a premium to sell houses located in very quiet areas (below $40 \mathrm{~dB}(\mathrm{~A})$ ). Residents in high-income areas were annoyed by noise at lower noise levels than other residents 
[29]. Bristow et al. [30] carried out an international meta-analysis of SP studies of transportation noise nuisance and found that rail noise values have a highly positive skewed distribution with few very high values beyond the 90th percentile, which thus have a high degree of uncertainty.

\subsection{Marginal cost of additional vehicles}

Andersson \& Ögren [10] estimated railway noise charges (as part of track access charges) using marginal cost principles, based on official Swedish monetary noise values from an HP value study, and found the marginal effect to be relatively insensitive to existing level of traffic. It has been found that locations with high traffic speed and/or density have lower marginal noise costs [15], suggesting that additional traffic has less impact in noisier areas, consistent with [12]. Ögren et al. [31] found significant variations in social marginal cost across the network, explained mainly by differences in population density.

\subsection{Other valuations and conclusions}

Bickel et al. [12] used WTP estimates based on UK house price HP studies to estimate the cost per train-km of different train types, producing a 1998 train noise cost of $€ 107$ million.

It can be concluded that (i) noise valuations can be presented in many different ways; (ii) economic valuations of noise vary widely and are context dependent; (iii) valuations used should reflect case study circumstances; and (iv) the larger the annoyance due to noise, the larger its valuation. In the UK, values of noise vary between $£ 10$ and over $£ 100$ per $\mathrm{dB}$ reduction per affected household per annum and are thus highly variable and uncertain.

\subsection{Values of vibration, ride quality and comfort}

Few studies were found to assign financial values to vibration or ride quality. This may be because passenger comfort and service quality perception are affected by multiple factors [32], including time, location, culture and the physical condition of passengers, and when the subjective contribution from all aspects is similar, then the optimum level of comfort will be achieved [33], regardless of individual factors' relative contributions.

Extensive research has been done on train vibration, particularly 'off-train' and ground vibrations (e.g. [34]), and on relationships between on-train vibration and ride quality, but much less on passenger valuation of these. Evidence indicates that on-board vibration is perceived by users as less of an issue than noise [18] and that noise can 'mask' and reduce the perception of vibration discomfort [35]. Howarth \& Griffin [36] produced an 'equivalence contour' to help determine whether reductions in noise or vibration would be more beneficial to residents near railway lines but provided no valuations. Sundström \& Shafiquzzaman [37] measured the threshold for comfortable reading/working on a train, but again without any economic valuation. It has been found [38] that users are more sensitive to vertical acceleration than to longitudinal or transverse acceleration. Perceptions of ride quality and comfort are related but distinct, since comfort is also influenced by other factors such as odours, noise, temperature, lighting, etc. Oborne [39] established some ride quality comfort thresholds, but also without financial valuations. Comfort can be improved by reducing train speed and thus vibration levels [40], but this would also increase travel and exposure time and is of questionable value. 


\section{EXPANDED CASE STUDY: THE LONDON-PORTSMOUTH LINE}

The findings of the preceding review were applied to a case study of the direct railway link between London Waterloo, Britain's busiest railway station and the south coast city of Portsmouth, via Woking and Guildford. In common with the majority of Britain's railways, this line was built in the 19th century, and the route includes some of the busiest sections of railway in Britain. London is the origin or destination of a majority of journeys on the route, trains operate at medium to high speed and there are important flows of commuter traffic.

The initial work on this case study, as described by Ortega et al. [9], assessed the economic effects of installing USPs on the route, focusing on the effects of the variables considered in the literature review, i.e. noise and comfort. As indicated above, the valuation of these variables can vary widely and therefore needs to be adjusted to a particular case study. Table 1 shows the minimum, central and maximum values that were used for the route, and the basis for their selection is set out in [9]. In particular, the valuation of noise was set to $£ 20$ per $\mathrm{dB}$ change, implying an average initial noise level in the range of 50-60 dB, consistent with noise maps for the line between Portsmouth and Waterloo.

A CBA-based economic assessment approach was used for the initial work and has been retained since, to enable the assessment and comparison of the costs and benefits of the different approaches relative to each other and to a base, 'do-nothing' scenario. In contrast to rail dampers and noise barriers, the effects and benefits of USP installation go beyond changes to noise levels and their installation costs and can be split into their subsequent effects on track maintenance \& renewal (M\&R), rolling stock, noise, comfort/ride quality and reliability. Table 2, again derived from [9], summarises the expected effects and whether their influences on the outcome of the CBA are considered positive, neutral or negative. As noted in [9], indirect effects such as avoided road congestion were excluded from the analysis.

The details of the derivation of the inputs to the CBA are included in [9], and it was noted that 'the installation of USPs could slightly increase air-borne noise but would more dramatically decrease ground-borne noise', and so their effects on air-borne and ground-borne noise were calculated separately, as shown below. Ground-borne noise arises from the transmission of vibrations caused by passing trains, and this is reduced when USPs isolate the track ballast from the rails and sleepers. However, air-borne noise (apart from that generated by trains themselves) is caused primarily by rail vibrations, as can be heard when a train approaches a

Table 1: Values used in the economic appraisal.

\begin{tabular}{|c|c|c|c|c|c|}
\hline Intervention & Variable & Measure & $\begin{array}{l}\text { Minimum } \\
\text { value }\end{array}$ & $\begin{array}{l}\text { Central } \\
\text { value }\end{array}$ & $\begin{array}{l}\text { Maximum } \\
\text { value }\end{array}$ \\
\hline \multirow[t]{4}{*}{ USPs } & Air-borne noise & $\begin{array}{l}\text { Noise increase for } \\
\text { affected households }\end{array}$ & $0 \mathrm{~dB}$ & $1 \mathrm{~dB}$ & $2 \mathrm{~dB}$ \\
\hline & $\begin{array}{l}\text { Ground-borne } \\
\text { noise }\end{array}$ & $\begin{array}{l}\text { Noise reduction for } \\
\text { affected households }\end{array}$ & $4 \mathrm{~dB}$ & $5 \mathrm{~dB}$ & $6 \mathrm{~dB}$ \\
\hline & Noise value & $\begin{array}{l}£ / d B \text { change/affected } \\
\text { household }\end{array}$ & - & $£ 20$ & - \\
\hline & $\begin{array}{l}\text { Comfort/ride } \\
\text { quality }\end{array}$ & $\begin{array}{l}\text { Value per passenger } \\
\text { (as \% of ticket price) }\end{array}$ & $0 \%$ & $1 \%$ & $2 \%$ \\
\hline
\end{tabular}


Table 2: USPs - expected effects on CBA assessment.

\begin{tabular}{llll}
\hline Intervention & Effect considered & $\begin{array}{l}\text { Evolution of the } \\
\text { variable }\end{array}$ & Anticipated effect on CBA \\
\hline USPs & Installation cost & Increase & Negative \\
& M\&R needs & Decrease & Positive \\
& Rolling stock & No change & Neutral \\
Air-borne noise & Increase & Negative \\
Ground-borne noise & Decrease & Positive \\
Comfort/ride quality & Increase & Positive \\
& Improved travel time & No change & Neutral \\
Induced demand & No change & Neutral (not considered) \\
Road congestion & Decrease & Neutral (not considered) \\
\hline
\end{tabular}

trackside listener, and the attenuation of these vibrations tends to be reduced by the installation of USPs, as the damping effect of the ballast is diminished [41].

To allow for the uncertainties inherent to the process, a stochastic approach was used to identify the range of potential benefits, 'underpinned by a sensitivity analysis, running multiple Monte Carlo simulations' in the spreadsheet-based model developed for the process, as described in $[8,9]$. The range of possible changes in noise levels along the route, multiplied by the corresponding noise valuations per household, was multiplied in turn by the affected number of households along the route, to obtain the possible range of economic benefits arising from noise reduction. Similarly, a range of potential ride quality/comfort benefits was calculated, based on varying percentages of ticket price, in the absence of an industry-standard approach. Otherwise, a standard CBA approach was used: the installation costs of USPs were calculated to obtain a base year present value of costs (PVC), as described in [9], and combined with the discounted future benefits to obtain a present value of benefits (PVB) in the same base year, arising from the calculated noise reduction, ride quality/comfort effects and $M \& R$ savings, to obtain a range of net present values (NPVs), as shown below. The analysis was based on an assumed project life of 60 years, with 2009 as a base year and an applied discount rate of $3.5 \%$. The results of the CBA are summarised in Table 3, as also shown in [9].

Table 3: USP installation: present values (2009 prices) for each stakeholder and impact.

\begin{tabular}{|c|c|c|c|c|}
\hline Variable & Stakeholder affected & $\begin{array}{l}\text { Most pes- } \\
\text { simistic } \\
\text { (£million) }\end{array}$ & $\begin{array}{l}\text { Central } \\
\text { (£million) }\end{array}$ & $\begin{array}{l}\text { Most optimistic } \\
\text { (£million) }\end{array}$ \\
\hline Air-borne noise & Non-users & -129.94 & -64.97 & 0 \\
\hline Ground-borne noise & Non-users & 101.77 & 127.21 & 152.65 \\
\hline Comfort/ride quality & Rail users and TOCs & 0 & 102.82 & 205.65 \\
\hline Financial benefit & Network Rail & 29.88 & 29.88 & 29.88 \\
\hline Total & & 1.71 & 194.94 & 388.18 \\
\hline
\end{tabular}


Three main conclusions were drawn from the results:

- All stakeholders potentially benefit from the intervention, including Network Rail as IM, train operators on the route and their users; the possible exception is non-users located between 80 and $300 \mathrm{~m}$ from the track, who may experience an increase in air-borne noise.

- The fairness/equity associated with the intervention is questionable, since the installation costs are incurred solely by Network Rail as IM, and, while Network Rail benefits from the intervention, greater benefits accrue to rail users and operators, and to non-users, for whom the net benefits are positive in all but the most pessimistic scenario. It may, however, be seen as good stewardship of the railway network and system, reducing its impact on nonusers, who, as taxpayers, contribute to its operation and upkeep, whether they use it or not.

- As indicated above, there is considerable uncertainty and variability in the results, but the overall outcome is positive in all cases, and the intervention is entirely within the control of IM and operators (i.e. there is no visual or other intrusion associated with it, requiring consent from external authorities), and it is a worthwhile means of upgrading 19th century infrastructure towards contemporary standards.

Following the work described in [9] and summarised above, the case study analysis was extended to assess the impacts and benefits of the installation of rail dampers or 2-m-high noise barriers as alternatives to USPs ( $2 \mathrm{~m}$ barriers are appropriate in this case, since there is no pantograph and negligible diesel engine noise to be reduced, due to the use of third rail electrification and low levels of diesel haulage, particularly south of Woking; they also have the additional advantage of not obscuring passengers' views from trains). The extended analysis is in some respects more straightforward than for USPs, as summarised in Table 4, since these interventions affect only the noise levels experienced by non-users and have no effect on the comfort and ride quality experienced by users or on the life and maintenance and renewal requirements of the track, although noise barriers may cause visual intrusion for nonusers. As in the case of most inter-urban and inter-city railway routes, population levels, and thus the numbers of non-users potentially affected by railway noise, vary considerably along the case study route, with higher population densities in the Portsmouth, Guildford, Woking and London areas, and along most of the route between Woking and London, and lower levels of population along the predominantly rural sections of the route between Havant (immediately north-east of Portsmouth) and Guildford. Because the installation of USPs provides benefits to the IM and to railway users as well as non-users, and the installation process is a relatively straightforward 'add-on' to normal track renewals, it makes sense to install them along the entire length of the route in question (although it would be interesting to consider the distribution of their benefits along the route). In the case of rail dampers and, especially,

Table 4: Rail dampers and noise barriers - expected effects on CBA assessment.

\begin{tabular}{llll}
\hline Intervention & Effect considered & $\begin{array}{l}\text { Evolution } \\
\text { of the variable }\end{array}$ & $\begin{array}{l}\text { Anticipated effect } \\
\text { on CBA }\end{array}$ \\
\hline Rail dampers & Installation cost & $\begin{array}{l}\text { Increase } \\
\text { Decrease }\end{array}$ & $\begin{array}{l}\text { Negative } \\
\text { Positive }\end{array}$ \\
Noise barriers & Installation cost & Increase & Negative \\
& Noise & Decrease & Positive \\
\hline
\end{tabular}


Table 5: Values used in the extended economic appraisal.

\begin{tabular}{|c|c|c|c|}
\hline Intervention & Variable & Impact & Unit economic benefit or cost \\
\hline \multirow[t]{2}{*}{ Rail dampers } & Noise & $5 \mathrm{~dB}$ noise reduction & $£ 100 /$ affected household \\
\hline & Cost & $\begin{array}{l}£ 125 \text { installation cost per } \\
\text { metre per rail }\end{array}$ & $£ 250 / \mathrm{m}$ (pair of rails) \\
\hline \multirow[t]{2}{*}{ Noise barriers } & Noise & $10 \mathrm{~dB}$ noise reduction & $£ 200 /$ affected household \\
\hline & Cost & $\begin{array}{l}£ 714 \text { installation cost per } \\
\text { metre per side of track }\end{array}$ & $£ 1,428 / \mathrm{m}$ (both sides of track) \\
\hline
\end{tabular}

noise barriers, however, partial installation is likely to be a more sensible and pragmatic option, reducing costs and providing noise reduction benefits where they are most needed, along the more built-up and heavily populated sections of the route. The extended analysis, therefore, covers both full and partial installation of rail dampers or noise barriers, comparing both with the central assessment of USPs. The anticipated impacts are summarised in Table 4, equivalent to Table 2 for USPs.

The noise reduction and cost values used in the extended analysis are shown in Table 5: the same noise reduction value of $£ 20 / \mathrm{dB} /$ affected household is used as previously, and the estimated costs were obtained from European Parliament values [42], converted into pound sterling and expressed in 2009-equivalent prices (note: the assumption of fixed valuations of noise reductions across different noise levels is a simplification, and subject to further work, as described below in Section 4).

As the local population levels vary along the case study route, so does the number of tracks, reflecting increased cumulative demand and traffic levels towards London: between London Waterloo and Clapham Junction, there is some variation, but the railway typically has eight tracks side-by-side, carrying main line and suburban train services between Waterloo and a range of destinations, including Portsmouth; between Clapham Junction and Woking Junction (immediately west of Woking station), the South West Main Line (SWML) is mainly four-track; between Woking Junction and Portsmouth, it is predominantly a two-track railway, with a short three-track section in the Portsmouth area between Fratton and Portsmouth $\&$ Southsea stations. The route characteristics are summarised, together with indicative population densities adjacent to the route, in Table 6.

While the noise reduction benefits depend upon the local population density and the number of households affected, the installation costs of rail dampers increase with the number of

Table 6: Track configurations and population densities along the case study route.

\begin{tabular}{lcll}
\hline Route section & $\begin{array}{c}\text { Length } \\
(\mathrm{km})\end{array}$ & $\begin{array}{l}\text { No. of } \\
\text { tracks }\end{array}$ & $\begin{array}{l}\text { Indicative population } \\
\text { density (people/km²) }\end{array}$ \\
\hline Waterloo-Clapham Jn. & 6.2 & 8 & $5,000-10,000$ \\
Clapham Jn.-Woking Jn. & 33.4 & 4 & $1,700-8,000$ \\
Woking Jn.-Fratton & 77.2 & 2 & $730-4,300$ \\
Fratton-Portsmouth \& Southsea & 1.3 & 3 & 5,000 \\
Portsmouth \& Southsea-Portsmouth Harbour & 1.3 & 2 & 5,000 \\
\hline
\end{tabular}


Table 7: Section lengths and track configurations selected for partial installation.

\begin{tabular}{lcl}
\hline Route section & Length $(\mathrm{km})$ & No. of tracks \\
\hline Waterloo-Clapham Jn. & 6.2 & 8 \\
Clapham Jn.-Woking Jn. & 30.7 & 4 \\
Woking Jn.-Fratton & 33.8 & 2 \\
Fratton-Portsmouth \& Southsea & 1.3 & 3 \\
Portsmouth \& Southsea-Portsmouth Harbour & 1.3 & 2 \\
\hline
\end{tabular}

tracks, giving noise barriers a comparative cost advantage as the number of tracks increases. Population density along the route was assessed at a more disaggregate level than that shown in Table 4, and 2,000 people $/ \mathrm{km}^{2}$ were selected as the minimum density justifying partial installation of rail dampers or noise barriers. This choice of cut-off point is partly arbitrary, but it reflects knowledge of the route as well as examination of the data, and the sections excluded from installation include Havant to Guildford (with the exception of Haslemere), which, apart from some small towns, is predominantly rural, and a section of the SWML east (i.e. on the London side) of Woking, close to the M25 London orbital motorway, which is also relatively sparsely settled and developed. The section lengths and track configurations for partial installation are summarised in Table 7.

It can be seen that $2.7 \mathrm{~km}$ of four-track railway is excluded from noise reduction measures between Clapham Jn. and Woking Jn. and $33.8 \mathrm{~km}$ between Woking Jn. and Fratton.

A similar, spreadsheet-based approach to that taken for the assessment of USPs was used to perform a CBA of the full and partial installation of rail dampers or noise barriers, the results of which are summarised in Table 8 in terms of present values of costs and benefits (PVC and PVB), NPV, all expressed in 2009 prices (consistent with [9]), and benefit-cost ratio (BCR).

Table 8: Comparative costs and benefits of different noise reduction options.

\begin{tabular}{|c|c|c|c|c|}
\hline $\begin{array}{l}\text { Noise reduction } \\
\text { intervention }\end{array}$ & PVC $(2009 £)$ & PVB $(2009 £)$ & NPV $(2009 £)$ & BCR \\
\hline USPs (full installation) & $£ 6 \mathrm{~m}$ & $£ 200.95 \mathrm{~m}$ & $£ 194.95 \mathrm{~m}$ & 33.5 \\
\hline $\begin{array}{l}\text { Rail dampers (full } \\
\text { installation) }\end{array}$ & $£ 86.15 \mathrm{~m}$ & $£ 452.06 \mathrm{~m}$ & $£ 365.91 \mathrm{~m}$ & 5.25 \\
\hline $\begin{array}{l}\text { Noise barriers (full } \\
\text { installation) }\end{array}$ & $£ 170.72 \mathrm{~m}$ & $£ 904.12 \mathrm{~m}$ & $£ 733.40 \mathrm{~m}$ & 5.30 \\
\hline $\begin{array}{l}\text { Rail dampers (partial } \\
\text { installation) }\end{array}$ & $£ 61.70 \mathrm{~m}$ & $£ 400.47 \mathrm{~m}$ & $£ 338.77 \mathrm{~m}$ & 6.50 \\
\hline $\begin{array}{l}\text { Noise barriers (partial } \\
\text { installation) }\end{array}$ & $£ 104.76 \mathrm{~m}$ & $£ 800.94 \mathrm{~m}$ & $£ 696.19 \mathrm{~m}$ & 7.65 \\
\hline $\begin{array}{l}\text { Rail dampers } \% \text { change, } \\
\text { partial vs. full }\end{array}$ & $-28.38 \%$ & $-11.41 \%$ & $-7.42 \%$ & $23.69 \%$ \\
\hline $\begin{array}{l}\text { Noise barriers } \% \\
\text { change, partial vs. full }\end{array}$ & $-38.64 \%$ & $-11.41 \%$ & $-5.07 \%$ & $44.37 \%$ \\
\hline
\end{tabular}


It can be seen that, while USP installation generates smaller PVB and NPV results than the other measures, even when taking the additional infrastructure maintenance benefits into account, their low installation costs and PVC result in a much higher BCR than for the other interventions, making this a particularly attractive intervention option from an economic standpoint.

The full installation of noise barriers along the case study route is approximately twice as expensive as the full installation of rail dampers, but, because of the enhanced noise reduction effects, it also delivers approximately twice the noise reduction benefits of rail dampers, and the resulting benefit:cost ratios are therefore similar.

Partial installation of rail dampers or noise barriers reduces the benefits by $11.4 \%$ in both cases, since the same proportion of the lineside population is affected in each case. The respective reductions in costs are $28.4 \%$ and $38.6 \%$, reflecting the relatively higher costs of rail damper installation in the multi-track locations where the population densities are higher and the interventions are retained. The corresponding increases in BCRs are $23.7 \%$ and $44.4 \%$, respectively: while these would not normally be used as criteria for choosing between investment options (NPV is the criterion used), they do reflect the comparative cost-effectiveness of noise barriers in multi-track situations. Even with partial installation of dampers or barriers, however, the resulting BCRs remain much smaller than for USPs, because of the latter's low installation costs.

\section{ONGOING AND FUTURE WORK}

The work described above provides a useful assessment of the absolute and relative costeffectiveness of three alternative approaches to railway noise reduction, undertaken in isolation. While USPs are relatively cheap to install and provide a wider range of IM, user and non-user benefits than rail dampers, they have been found to result in additional noise levels for some non-users, as reported in [9] and indicated above. There may therefore be a case in some situations for the use of a combination of USPs and rail dampers or noise barriers, depending upon the proximity of non-users to the track, the levels of railway-generated noise, and, as indicated in Table 8 and the associated discussion, the numbers of tracks and the comparative costs and benefits of rail dampers and barriers. However, the situation is complicated by the fact that the combined effects of different interventions are not simply additive, i.e. the resulting total noise reductions are not necessarily the sum of their parts.

Work is therefore ongoing to develop more sophisticated assessments and valuations of the noise reductions provided by USPs, rail dampers and noise barriers, individually and in combination, for different numbers of tracks and at a range of different ambient noise levels, degrees of reduction and distances from the railway, providing more detailed information than is available from the use of the single, 'one size fits all' values quoted above. Separate assessments are being undertaken for air-borne and ground-borne noise.

As noted in $[9,43]$, other noise reduction measures are available, including vehicle-based noise reduction measures and the sound insulation of affected residential and commercial buildings, but these remain beyond the scope of the extended analysis. It is, however, planned to extend the use of geographic information system (GIS) techniques beyond the work that has already been done to identify affected buildings and populations, to develop more detailed and disaggregate understanding of affected non-user locations, distributions and population densities and to combine these with the improved noise maps to enable more precise assessments of the costs and benefits of alternative approaches to the reduction of railway-related noise. 
In the longer term, it is planned to investigate and develop an ontology-based approach to the modelling and assessment of noise reduction and other infrastructure, timetable or rolling stock interventions, providing a standardised and flexible framework for economic, carbon and other assessments.

\section{CONCLUSIONS}

To ensure the efficient allocation of scarce resources, particularly in the recent and ongoing economic climate, significant transport (and other) investments should be subject to careful forecasting and assessment of the likely costs and benefits, typically by means of a more-orless formal CBA. Formal CBA approaches were originally developed for, and are typically applied to, the planning of and capital investment in new infrastructure and the identification of preferred options, but they can also be usefully applied to 'current investments' in existing infrastructure, including the maintenance and renewal (M\&R) of railway track.

In the course of routine maintenance and (particularly) renewal works, the opportunity may arise to include additional interventions, such as the installation of USPs, rail dampers or noise barriers (although the latter are likely to require significant additional works for their erection). Such interventions should be subject to a rigorous CBA or equivalent assessment, including as many quantifiable economic effects as possible, in addition to costs, reflecting as fully as possible the benefits (and disbenefits) to affected stakeholders, including the IM, train operators, users and non-users alike.

As indicated above, and in more detail in [9], the availability and quality of data relating to benefits are uneven and subject to variability and uncertainty. While the nature and effects of railway noise are well understood, particularly in the case of non-users, valuations of noise reduction vary widely, while the effects of noise, vibration and ride quality and comfort (and changes in these) on railway users are much less well understood. For these reasons, where appropriate, a range of values should be sampled from, and the results subjected to sensitivity analysis, to improve the validity of and confidence in the results obtained.

For the purposes of extending the analysis described in [9], the costs and noise reduction benefits of rail dampers and 2-m-high noise barriers were compared with the results previously obtained for USPs, although USPs provide additional ride quality/comfort benefits to railway passengers, and maintenance savings benefits to Network Rail, as the IM.

The conclusions to be drawn from the expanded work in some respects resemble those from the USP-only case study described in [9] and summarised above, but there are also differences:

- Non-users (including those who do not benefit from USPs) benefit from the noise reduction resulting from the introduction of rail dampers or noise barriers, but there is no direct benefit to users, operators or Network Rail as IM

- Equity-related issues apply to the installation of rail dampers or noise barriers and are considerably greater than for USPs, since the installation costs are higher, and the IM receives no direct benefits as a result, apart from potentially being seen as a 'good neighbour' by non-users

- Issues of uncertainty continue to apply to the valuations and analysis of noise reductions, and these will be addressed by the ongoing and future work

The installation of rail dampers or noise barriers provides a much greater reduction of noise to non-users than USPs, but without the additional user and IM benefits, and at a much greater 
(by an order of magnitude or more) cost, resulting in greatly inferior benefit:cost ratios. These can be improved by selective, partial installation of dampers or barriers, but only slightly, and should be the subject of careful analysis to ensure that circumstances justify the expense. This reiterates and emphasises the role for and importance of rigorous CBAs when considering the renewal and possible upgrading of existing infrastructure and also the potential benefits of the planned ontology-based analysis framework in providing a comprehensive and flexible means of appraising future interventions.

\section{ACKNOWLEDGEMENTS}

This research has been carried out by the authors as part of the EPSRC-funded TRACK21 (EP/H044949/1) and Track to the Future projects (EP/M025276/1). The lab test results and other parameters such as cost of USPs have been supplied by other researchers working on the project. However, the named authors are responsible for the review of the test results and the conclusions presented here. The data used in this research have been deposited in the University of Southampton library: https://doi.org/10.5258/SOTON/D0129.

\section{REFERENCES}

[1] Frost, M.W., Ison, S.G. \& Watson, R., UK rail transport: A review of demand and supply. Proceedings of the ICE - Transport, 165(3), pp. 225-234, 2012, https://doi. org/10.1680/tran.10.00028.

[2] Powrie, W., On track: The future for rail infrastructure systems. Proceedings of the Institution of Civil Engineers - Civil Engineering, 167(4), pp. 177-185, 2014, https:// doi.org/10.1680/cien.14.00014.

[3] Ortega, A., Vassallo, J., Guzmán, A. \& Pérez-Martínez, P., Are longer and heavier vehicles (LHVs) beneficial for society? A cost benefit analysis to evaluate their potential implementation in Spain. Transport Reviews: A Transnational Transdisciplinary Journal, 34(2), pp. 150-168, 2014, https://doi.org/10.1080/01441647.2014.891161.

[4] Salling, K. \& Nielsen, O., Uncertainties in transport project evaluation: Editorial. European Journal of Transport and Infrastructure Research, 15(3), pp. 282-285, 2015, https://doi.org/10.18757/ejtir.2015.15.3.3076.

[5] Asplund, D. \& Eliasson, J., Does uncertainty make cost-benefit analyses pointless? Transportation Research Part A: Policy and Practice, 92, pp. 195-205, 2016, https:// doi.org/10.1016/j.tra.2016.08.002.

[6] Track to the Future (T2F), available at https://t2f.org.uk/ (accessed 14 November 2018).

[7] Schilder, R., USP (under sleeper pads): A contribution to save money in track maintenance. AusRAIL PLUS, Driving the Costs Out of Rail, 2013.

[8] Ortega, A., Blainey, S. \& Preston, J., Installation of under sleeper pads on ballasted railway track: An economic analysis of their potential implementation. Proceedings of the Institution of Mechanical Engineers, Part F: Journal of Rail and Rapid Transit, 232(6), pp. 1800-1813, 2017, https://doi.org/10.1177/0954409717748811.

[9] Ortega, A., Blainey, S., Preston, J., Thompson, D., Squicciarini, G., Ntotsios, E. \& Armstrong, J., Noise reduction for ballasted track: A socio-economic assessment. Ashurst: WIT Transactions on Ecology and the Environment, Vol. 181. WIT Press, 2018, ISSN 1743-3509.t.

[10] Andersson, A. \& Ogren, M., Noise charges in railway infrastructure: A pricing schedule based on the marginal cost principle. Transport Policy, 14, pp. 204-213, 2007, https:// doi.org/10.1016/j.tranpol.2007.01.002. 
[11] De Coensel, B., Botteldooren, D., Berglund, B., Nilsson, M.E., De Muer, T. \& Lercher, P., Experimental investigation of noise annoyance caused by high-speed trains. Acta Acustica United with Acustica, 93(4), pp. 589-601, 2007, 1854/10361.

[12] Bickel, P., Friedrich, R., Link, H., Stewart, L. \& Nash, C., Introducing environmental externalities into transport pricing: Measurement and implications. Transport Reviews: A Transnational Transdisciplinary Journal, 26(4), pp. 389-415, 2006, https://doi. org/10.1080/01441640600602039.

[13] Staatsen, B., Nijland, H.A., van Kempem E.M.M., de Hollander A.E.M., Franssen, A.E.M. \& van Kamp, I., Assessment of health impacts and policy options in relation to transport-related noise exposures, RIVM Report, Bilthoven: RIVM (Netherlands National Institute for Public Health and the Environment), 2004.

[14] Brons, M., Nijkamp, P., Pels, E. \& Rietveld, P., Railroad noise: Economic valuation and policy. Transportation Research D, 8, pp. 169-184, 2003, https://doi.org/10.1016/ S1361-9209(02)00048-2.

[15] Nash, C., Unification of Accounts and Marginal Costs for Transport Efficiency: Final Report, ITS, University of Leeds, available at http://www.its.leeds.ac.uk/projects/unite/ downloads/Unite\%20Final\%20Report.pdf (accessed 19 March 2018).

[16] Strand, J. \& Vagnes, M., The relationship between property values and railroad proximity: A study based on hedonic prices and real estate brokers' appraisals. Transportation, 28, pp. 137-156, 2001, https://doi.org/10.1023/A:1010396902050.

[17] Bristow, A., Wardman, M. \& Chintakayala, V., International meta-analysis of stated preference studies of transportation noise nuisance. Transportation, 42, pp. 71-100, 2015, https://doi.org/10.1007/s11116-014-9527-4.

[18] Navrud, S., Trædal, Y., Hunt, A., Longo, A., Greßmann, A., Leon, C. \& Meszaros, F., Economic values for key impacts valued in the stated preference surveys, developing harmonised European approaches for transport costing and project assessment (HEATCO), available at http://heatco.ier.uni-stuttgart.de/HEATCO_D4.pdf (accessed 19 March 2018).

[19] Nijland, H., van Kempen, E., van Wee, G. \& Jabben, J., Costs and benefits of noise abatement measures. Transport Policy, 10, pp. 131-140, 2003, https://doi.org/10.1016/ S0967-070X(02)00064-1.

[20] WebTAG: TAG data book. December 2017, Department for transport, available at https://www.gov.uk/government/publications/webtag-tag-data-book-december-2017 (accessed 19 March 2018).

[21] Weinberger, M., Thomassen, H. \& Willeke, R., Kosten des Larms in der Bundesrepublik Deutschland, Erich Schmidt Verlag: Berlin, 1991.

[22] Oertli, J. \& Wassmer, D., Rail noise control in Switzerland: Legislation, environment, politics and finances. Journal of Sound and Vibration, 193, pp. 403-406, 1996, https:// doi.org/10.1006/jsvi.1996.0282.

[23] Tyssen, L., Consequenties van Voorgenomen Woningbouwplannen van het Aanhouden van Grenswaarden met betrekking tot Spoorweglawaai, Transportation, 28, pp. 137156, 1982.

[24] Howarth, A., Pearce, D.W., Ozdemiroglu, E., Seccombe-Hett, T., Wieringa, K., Streefkerk, C.M. \& Hollander, A.E.M., Valuing the benefits of environmental policy: the Netherlands. RIVM Report, 2001.

[25] van Kempen, E., Een schatting van de baten van geluidmaatregelen. RIVM Report, 2001. 
[26] Surface Transport Costs and Charges Great Britain 1998, Institute for Transport Studies, University of Leeds, available at http://www.its.leeds.ac.uk/fileadmin/user_upload/ Surface_Transport_Costs_and_Charges_Great_Britain_2001.pdf (accessed 19 March 2018).

[27] The Valuation of Transport-Related Noise in Birmingham,. University of East Anglia, available at http://webarchive.nationalarchives.gov.uk/20060715203622/http:/www. dft.gov.uk/stellent/groups/dft_econappr/documents/page/dft_econappr_032868.pdf (accessed 19 March 2018).

[28] Nellthorp, J., Bristow, A.L. \& Day, B., Introducing willingness-to-pay for noise changes into transport appraisal: An application of benefit transfer. Transport Reviews: A Transnational Transdisciplinary Journal, 27(3), pp. 327-353, 2007, https://doi. org/10.1080/01441640601062621.

[29] Theebe, M.A., Planes, trains and automobiles: The impact of traffic noise on house prices. Journal of Real Estate, Finance and Economics, 28(2/3), pp. 209-234, 2004, https://doi.org/10.1023/B:REAL.0000011154.92682.4b.

[30] Bristow, A., Wardman, M. \& Chintakayala, V., International meta-analysis of stated preference studies of transportation noise nuisance. Transportation, 42, pp. 71-100, 2015, https://doi.org/10.1007/s11116-014-9527-4.

[31] Ögren, M., Swärdh, J.-E., Andersson, H. \& Jonsson, L., Noise charges for Swedish railways based on marginal cost calculations, available at https://www.diva-portal.org/ smash/get/diva2:674191/FULLTEXT01.pdf, 2011 (accessed 19 March 2018).

[32] Grujičić, D., Ivanović, I., Jović, J. \& Đorić, V., Customer perception of service quality in public. Transport, 29(3), pp. 285-295, 2014, https://doi.org/10.3846/16484142.2014.95 1685.

[33] Hardy, A., Measurement and assessment of noise within passengers trains. Journal of Sound and Vibration, 231(3), pp. 819-829, 2000, https://doi.org/10.1006/ jsvi.1999.2565.

[34] Kouroussis, G., Connolly, D. \& Verlinden, O., Railway-induced ground vibrations - A review of vehicle effects. International Journal of Rail Transportation, 2(2), pp. 69-110, 2014, https://doi.org/10.1080/23248378.2014.897791.

[35] Huang, Y. \& Griffin, M., The discomfort produced by noise and whole-body vertical vibration presented separately and in combination. Ergonomics, 57(11), pp. 1724-1738, 2014, https://doi.org/10.1080/00140139.2014.943683.

[36] Howarth, H.V.C. \& Griffin, M.J., The relative importance of noise and vibration from railways. Applied Ergonomics, 21(2), pp. 129-34, 1990, https://doi.org/10.1016/00036870(90)90135-K.

[37] Sundström, J. \& Shafiquzzaman, K., Influence of stationary lateral vibrations on train passengers' difficulty to read and write. Applied Ergonomics, 39(6), pp. 710-718, 2008, https://doi.org/10.1016/j.apergo.2007.11.009.

[38] Castellanos, J.C. \& Fruett, F., Embedded system to evaluate the passenger comfort in public transportation based on dynamical vehicle behavior with user's feedback. Measurement, 47, pp. 442-451, 2014, https://doi.org/10.1016/j.measurement.2013.08.068.

[39] Oborne, D.J., Vibration and passenger comfort: Can data from subjects be used to predict passenger comfort? Applied Ergonomics, 9(3), pp. 155-61, 1978, https://doi. org/10.1016/0003-6870(78)90006-6.

[40] Karakasis, K., Skarlatos, D. \& Zakinthinos, T., A factorial analysis for the determination of an optimal train speed with a desired ride comfort. Applied Acoustics, 66(10), pp. 1121-1134, 2005, https://doi.org/10.1016/j.apacoust.2005.02.006. 
[41] Triepaischajonsak, N., The effect of sleeper soffit pads on railway noise. Dissertation submitted in partial fulfilment of the requirements for the degree of MSc, University of Southampton, UK, 2008.

[42] European Parliament: Directorate General for Internal Policies. Reducing Railway Noise Pollution, available at http:/www.europarl.europa.eu/RegData/etudes/etudes/ join/2012/474533/IPOL-TRAN_ET(2012)474533_EN.pdf, 2012 (accessed 9 November 2018).

[43] Real cost of railway noise mitigation; UIC, available at https://uic.org/IMG/pdf/ba7041101-100-md-af20130168-lok_final_report_uic_real_costs_30jan13.pdf, (accessed 19 March 2018). 